\title{
PENYULUHAN NILAI-NILAI PANCASILA KEPADA ORGANISASI SISWA INTRA SEKOLAH (OSIS) SEKOLAH MENENGAH KEJURUAN (SMK) NEGERI 39 JAKARTA
}

\author{
Lusy Liany ${ }^{*}$, Ely Alawiyah Jufri, Mohammad Kharis Umardani \\ ${ }^{l}$ Fakultas Hukum, Universitas YARSI, Jakarta \\ Jl. Letjen Suprapto, Cempaka Putih, Jakarta Pusat, 021-4269288 \\ * Penulis Korespondensi: lusy.liany@yarsi ac.id
}

\begin{abstract}
ABSTRAK
Pancasila bagi masyarakat Indonesia bukanlah suatu hal yang baru dan asing. Pancasila terdiri dari lima sila yang tertuang dalam Pembukaan UUD 1945 Alinea ke-IV dan diperuntukkan sebagai dasar negara Republik Indonesia. Di Indonesia, pelaksanaan pendidikan nasional diatur dalam UU No. 20 Tahun 2003 Tentang Pendidikan Nasional. Pasal 2 UU No. 20 Tahun 2003 menyebutkan bahwa: "Pendidikan nasional berdasarkan Pancasila dan Undang-Undang Dasar Negara Republik Indonesia Tahun 1945. Pada saat ini Pancasila seiring dengan perkembangan dan perubahan zaman yang begitu pesat dan kompleks yakni di era globalisasi ini,moralsiswa-siswi Indonesia mulai dipertanyakan. Di tengah hegemoni media, revolusi iptek tidak hanya mampu menghadirkan sejumlah kemudahan dan kenyamanan hidup bagi manusia modern, melainkan juga mengundang serentetan permasalahan dan kekhawatiran terhadap kepribadian bagi seluruh bangsa Indonesia khususnya dalam hal ini para siswa-siswa. Untuk itulah, pemberian materi tentang nilainilai Pancasila kepada siswa-siswi mutlak diperlukan supaya para siswa-siswa agar dapat memahami nilainilai yang terdapat didalam Pancasila itu sendiri sehingga dapat menerapkannya dalam kehidupan berbangsa,bernegara dan bermasyarakat.
\end{abstract}

Kata Kunci: Pancasila,Nilai-Nilai,OSIS.

\section{ABSTRACT}

Pancasila for the Indonesian people is not something new and unfamiliar. Pancasila consists of five precepts contained in the 1945 opening paragraph of all IV and designated as the foundation of the Republic of Indonesia. In Indonesia, the implementation of national education stipulated in Law No. 20 Year 2003 on National Education. Article 2 of Law No. 20 of 2003 states that: "The national education based on Pancasila and the Constitution of the Republic of Indonesia Year 1945. At this time Pancasila along with the development and the changing times is so rapid and complex that in this era of globalization, moralsiswaIndonesian student was questioned. In the center of media hegemony, a revolution in science and technology is not only able to present a number of conveniences and comforts of life for modern humans, but also invited a spate of issues and concerns about the personality of the people of Indonesia, especially in this case the students. For this reason, the provision of material about the values of Pancasila to students is absolutely necessary in order for the students to understand the values contained in Pancasila itself so that it can apply in the life of the nation, the state and society.

Keywords: Pancasila, Values, OSIS.

Pancasila bagi masyarakat Indonesia bukanlah suatu hal yangbaru dan asing. Pancasila terdiri dari lima sila yang tertuang dalam Pembukaan UUD 1945 Alinea ke-IV dan diperuntukkan sebagai dasar negara Republik Indonesia. Meskipun didalam Pembukaan UUD 1945 tesebut tidak secara eksplisit kata Pancasila sebagai Dasar Negara, namun hal ini dapat dibuktikan dalam sejarah pembentukannya Pancasila itu sendiri sebagai dasar negara.Kesepakatan bangsa menetapkan Pancasila sebagai dasar Negara Kesatuan Republik Indonesia (NKRI) dinyatakan pada 18 Agustus 1945 oleh PPKI sebaga lembaga pembentuk negara (Winarno, 2006). 
Selain sebagai dasar negara, Pancasila merupakan ideologi bangsa Indonesia yang terlahir dari kebudayaan dan sejarah masyarakat Indonesia yang telah ada jauh sebelum bangsa Indonesia merdeka.Pancasila sebagai ideologi bangsa Indonesia memiliki nilai luhur yang tercermin dalam sila-sila Pancasila.

Ketuhanan Yang Maha Esa yang terdapat pada sila pertama Pancasila menunjukkan bahwa Bangsa Indonesia menempatkan Tuhan pada kedudukan yang paling tinggi dan hal ini bukanlah suatu nilai yang tiba-tiba muncul (Faizin, 2013).

Pancasila sebagai ideologi bangsa Indonesia memiliki nilai-nilai luhur.Nilainilai pancasila menjadi sumber segala aturan baik aturan yang bersifat fomal maupun informal. Pendidikan nasional merupakan aspek pokok yang harus berlandasakn pancasila. Hal ini dapat dilihat dalam Pasal 2 UU No. 20 Tahun 2003 Tentang Pendidikan Nasional dalam Pasal 2 yang menyebutkan bahwa: "Pendidikan nasional berdasarkan Pancasila dan Undang-Undang Dasar Negara Republik Indonesia Tahun 1945”.

Berdasarkan Undang-Undang no. 20 Tahun 2003 tentang Pendidikan Nasional, menyatakan bahwa pendidikan nasional berfungsi mengembangkan kemampuan dan membentuk watak serta peradaban bangsa yang bermartabat dalam rangka mencerdaskan kehidupan bangsa, bertujuan untuk berkembangnya potensi peserta didik agar menjadi manusia yang beriman dan bertakwa kepada Tuhan Yang Maha Esa, berakhlak mulia, sehat, berilmu, cakap, kreatif, mandiri, dan menjadi warga negara yang demokratis serta bertanggung jawab."

Dewasa ini, terutama di era reformasi membicarakan Pancasila
VOLUME 1 NOMOR 1 TAHUN 2017

(Halaman 1-52)

dianggap sebagai keinginan untuk kembali ke kejayaan masa Orde Baru. Bahkan, sebagian orang memandang sinis tehadap Pancasila sebagai sesuatu yang salah. Kecenderungan demikian wajar karena pada masa Orde Baru menjadi Pancasila sebagai legitimasi ideologis dalam rangka mempertahankan dan memperluas kekuasaannya secara masif.Namun, sebagai dasar negara dan ideologi nasional, nilai-nilai yang terkandung didalam Pancasila layak untuk dikaji dan diterapkan dalam kehidupan berbangsa dan bernegara (Winarno, 2006).

Melalui perjalanan panjang negara Indonesia sejak merdeka hingga saat ini, Pancasila ikut berproses pada kehidupan bangsa Indonesia.Pancasila dari awal dibentuk sampai saat ini tetap sebagai dasar negara namun interpretasi dan perluasan maknanya ternyata digunakan untuk kepentingan kekuasaan yang silih berganti.Pada akhirnya dengan keluarnya Ketetapan MPR No.XVIII/MPR/1998 tentang Pencabutan Ketetapan MPR RI No.II/MPR/1978 tentang Pedoman Penghayatan dan Pengamalan Pancasila (Winarno, 2006).

Dengan keluarnya Ketetapan MPR diatas tujuannya agar tidak terjadi lagi kesalahan dalam memperlakukan Pancasila dalam kehidupan bernegara, namun hal ini bukan berarti mematikan nilai-nilai Pancasila itu sendiri.Pancasila hendaknya diperlakukan secara benar dan wajar dalam konteks kehidupan berbangsa, bernegara dan bermasyarakat. Jangan sampai Pancasila hanya sebagai lips service dan nilai-nilainya tidak lagi diterapkan dalam kehidupan berbangsa,bernegara dan bermasyarakat. Dalam istilah lain Kaelan menyatakan perlunya aktualisasi Pancasila baik aktualisasi Pancasila secara subjektif 
yaitu realisasi nilai-nilai Pancasila pada setiap individu maupun aktualisasi objektif yaitu realisasi dalam segala aspek kenegaraan dan hukum (Kaelan, 2002).

Pelaksanaan nilai-nilai Pancasila merupakan suatu kewajiban bagi seluruh masyarakat Indonesia khususnya dalam hal ini para anggota OSIS SMK N 39 Jakarta. Dengan adanya pemahaman dan pelaksanaan nilai-nilai Pancasila diharapakan dapat dijadikan salah satu cara untuk mendukung tujuan pendidikan nasional di Indonesia. Selain itu, penyuluhan ini dilakukan dengan tujuan untuk memberikan pemahaman kepada OSIS SMK N 39 Jakarta tentang nilai-nilai apasajakah yang terdapat didalam Pancasila. Setelah kegiatan ini selesai dilakukan, maka diharapkan pengetahuan yang didapat dapat diterapkan dalam kehidupan berbangsa, bernegara dan bermasyarakat.

\section{METODE}

Kegiatan pengabdian kepada masyarakat ini dilakukan dengan metode participatory action dalam bentuk ceramah dan diskusi. Pelaksanaan metode ini digunakan waktu sebanyak $40 \%$ untuk penyampaian materi atau ceramah sedangkan sisanya $60 \%$ digunakan untuk diskusi dan tanya jawab. Diharapkan dengan pendekatan yang bersifat partisipatif ini, peserta dapat secara maksimal memahami dan ikut mempraktekkan langsung apa yang telah diperoleh melalui penyuluhan.

Pada awalnya akan dilakukan tes awal (pre test) untuk mengungkap seberapa jauh pengetahuan OSIS tentang nilai-nilai apasaja yang terdapat didalam Pancasila. Kemudian dilakukan pembekalan materi dan diakhiri dengan tanya jawab atau diskusi. Setelah dilakukan pembekalan materi dan diskusi, akan dievaluasi dengan tes akhir (post test) untuk mengetahui apakah materi dapat dipahami oleh para OSIS tersebut.

\section{HASIL DAN PEMBAHASAN}

Kegiatan penyuluhan dilakukan pada tanggal Jumat, 3 Februari 2017 dan berlangsung dari pukul 09.00-12.00 WIB. Kegiatan bertempat di SMKN 39 Jakarta Jl. Cempaka Putih Tengah VI/2. Kegiatan ini diikuti oleh 55 orang Anggota Osis dan Pengurus Ekstrakuliker lainnya.

Materi penyuluhan diawali dengan pemberian pengetahuan tentang Pancasila sebagai dasar negara yang dilanjutkan dengan pemberian materi mengenai pemahaman Pancasila sebagai ideologi negara. Kemudian dilanjutkan dengan presentasi mengenai nilai-nilai yang terdapat didalam Pancasila.

Pertama, penjelasan tentang Pancasila sebagai dasar negara. Secara umum Pancasila sebagai dasar negara diartikan sebagai Pancasila dipergunakan sebagai dasar untuk mengatur pemerintahan dan mengatur penyelenggaraan negara. Kedua, penjelasan tentang Pancasila sebagai Ideologi Negara. Ideologi berintikan seperangkat nilai yang bersifat menyeluruh dan mendalam yang dimiliki dan dipegang oleh seseorang atau suatu masyarakat sebagai wawasan atau pandangan hidup mereka. Penjelasan yang terakhir adalah tentang Nilai-nilai dalam Pancasila. Secara umum ada lima nilai yang terdapat didalam Pancasila: 1) nilai ketuhanan; 2) nilai kemanusiaan; 3) nilai persatuan; 4) nilai kerakyatan; dan 5) nilai keadilan. 


\section{PEMBAHASAN}

Seperti telah diuraikan sebelumnya bahwa terdapat 3 (tiga) materi yang diberikan dalam penyuluhan ini. Pertama, penjelasan tentang Pancasila sebagai dasar negara yang dilanjutkan dengan pemberian materi mengenai pemahaman Pancasila sebagai ideologi negara. Kemudian dilanjutkan dengan presentasi mengenai nilai-nilai yang terdapat didalam Pancasila.

\section{Pancasila Sebagai Dasar Negara}

Pancasila sering disebut sebagai dasar falsafah negara (dasar filsafat negara) dan ideologi negara. Pancasila dipergunakan sebagai dasar untuk mengatur pemerintahan dan mengatur penyelenggaraan negara. Konsep-konsep Pancasila tentang kehidupan bernegara yang disebut cita hukum (staatsidee), merupakan cita hukum yang harus dilaksanakan secara konsisten dalam kehidupan berbangsa dan bernegara. Pancasila juga mempunyai fungsi dan kedudukan sebagai pokok atau kaidah negara yang mendasar (fundamental norma) (Darmodiharjo dan Sidharta, 1995). Kedudukan Pancasila sebagai dasar negara bersifat tetap, kuat, dan tidak dapat diubah oleh siapapun, termasuk oleh MPRDPR hasil pemilihan umum. Mengubah Pancasila berarti membubarkan Negara Kesatuan Republik Indonesia yang diproklamasikan pada tanggal 17 Agustus 1945.

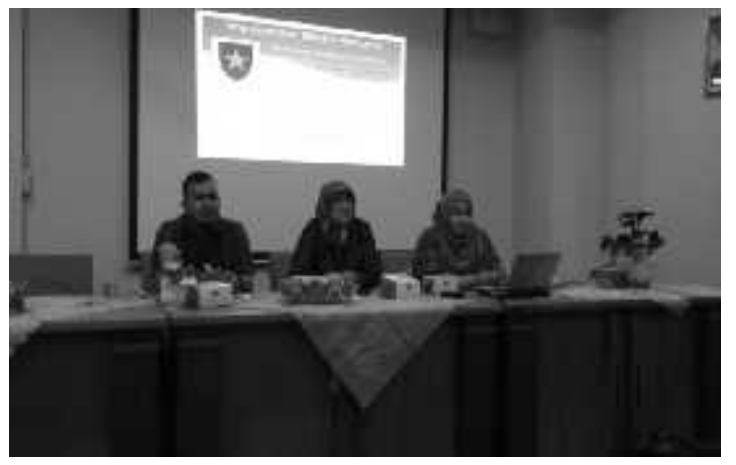

Gambar 1.Pemberian Materi

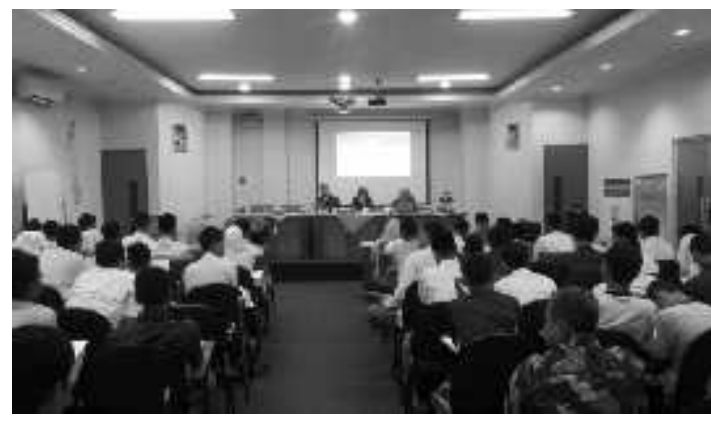

Gambar 2. Sesi tanya jawab

Pengertian pancasila sebagai dasar negara, sesuai dengan bunyi Pembukaan UUD 1945 pada alinea keempat, yaitu:

"..., maka disusunlah kemerdekaan kebangsaan Indonesia dalam suatu Undang-Undang Dasar Negara Indonesia yang berkedaulatan rakyat dengan berdasarkan kepada; Ketuhanan Yang Maha Esa; kemanusiaan yang adil dan beradab, persatuan Indonesia, kerakyatan yang dipimpin oleh hikmat kebijaksanaan dalam permusyawaratan/perwakilan, serta dengan mewujudkan suatu keadilan sosial bagi seluruh rakyat Indonesia”.

Pancasila sebagai dasar negara menjadikan setiap tingkah laku dan setiap pengambilan keputusan para penyelenggara negara dan pelaksana pemerintahan harus selalu berpedoman pada Pancasila, dan tetap memelihara budi pekerti kemanusiaan yang luhur serta memegang teguh cita-cita moral bangsa. Darmodiharjo dan Sidharta (1995), menyatakan bahwa Pancasila memenuhi syarat sebagai dasar negara bagi Negara Kesatuan Republik Indonesia dengan alasan sebagai berikut:

a. Pancasila memiliki potensi menampung keadaan pluralistik masyarakat Indonesia yang beraneka ragam suku, agama, ras dan antar golongan. Pada Sila Ketuhanan Yang Maha Esa, menjamin kebebasan untuk beribadah sesuai agama dan keyakinan 
masing-masing. Kemudian pada Sila Persatuan Indonesia, mampu mengikat keanekaragaman dalam satu kesatuan bangsa dengan tetap menghormati sifat masing-masingseperti apa adanya.

b. Pancasila memberikan jaminan terealisasinya kehidupan yang pluralistik, dengan menjunjung tinggi dan menghargai manusia sesuai dengan harkat dan martabatnya sebagai makhluk Tuhan secara berkeadilan yang disesuaikan dengan kemampuan dan hasil usahanya. Hal ini ditunjukkan dengan Sila Kemanusiaan Yang Adil dan Beradab.

c. Pancasila memiliki potensi menjamin keutuhan Negara Kesatuan Republik Indonesia yang terbentang dari Sabang sampai Merauke, yang terdiri atas ribuan pulau sesuai dengan Sila Persatuan Indonesia.

d. Pancasila memberikan jaminan berlangsungnya demokrasi dan hakhak asasi manusia sesuai dengan budaya bangsa. Hal ini, selaras dengan Sila Kerakyatan yang dipimpin oleh hikmat kebijaksanaan dalam permusyawaratan/perwakilan.

e. Pancasila menjamin terwujudnya masyarakat yang adil dan sejahtera sesuai dengan Sila Keadilan sosial bagi seluruh rakyat sebagai acuan dalam mencapai tujuan tersebut Pancasila sebagai kaidah negara yang fundamental berarti bahwa hukum dasar tertulis (UUD), hukum tidak tertulis (konvensi), dan semua hukum atau peraturan perundang-undangan yang berlaku dalam negara Republik Indonesia harus bersumber dan berada dibawah pokok kaidah negara yang fundamental tersebut (Asshiddiqie, 2009).

2. Pancasila sebagai Ideologi Negara

Makna Pancasila sebagai Ideologi Negara, ideologi secara umum merupakan sistem keyakinan yang dianut oleh masyarakat untuk menata dirinya sendiri. Ideologi menjadi pusat perdebatan banyak pakar di Amerika Serikat pada era setelah Perang Dingin setelah Perang Dunia II. Dua pendapat yang terkenal antara lain Daniel Bell yang menyimpulkan dalam bukunya Matinya Ideologi telah meramalkan bahwa ideologi telah sampai kepada ajalnya(Asshiddiqie, 2009). Dan ramalan itu terbukti dengan hancurnya komunisme pada abad 20. Kehancuran komunisme seakan-akan membenarkan "ideologi yang baru" seperti yang telah dicetuskan oleh Francis Fukuyama dalam bukunya The end of history and the last men. Namun bagaimanapun juga tesis Fukuyama merupakan suatu ideologi baru yaitu kepercayaan pada ideologi liberalisme.

Istilah ideologi pertama kali digunakan oleh seorang filsuf Perancis, Destutt de Tracy, pada tahun 1796. Destutt de Tracy menggunakan kata ideologi untuk menunjuk pada suatu bidang ilmu yang otonom, ialah analisis ilmiah dari berpikir manusia, otonom dalam arti lepas dari metafisika tetapi juga untuk mendefinisikan "sains tentang ide". Ideologi dapat dianggap sebagai visi yang komprehensif, sebagai cara memandang segala sesuatu (bandingkan Weltanschauung) sebagai akal sehat dan beberapa kecenderungan filosofis, atau sebagai serangkaian ide yang dikemukakan oleh kelas masyarakat yang dominan kepada seluruh anggota masyarakat (definisi ideologi Marxisme). 
Dalam sejarah di Indonesia, ideologi seringkali dianut karena manfaatnya. Akan tetapi orang menganut dan mendukung suatu ideologi pada dasarnya juga karena keyakinan bahwa ideologi itu benar. Ide-ide atau pengertian itu merupakan suatu sistem, suatu perangkat yang menjadi suatu kesatuan, menjadi ideologi mengenai manusia dan seluruh realitas (Usman, 1993).

Ideologi berasal dari kata idea (Inggris), yang artinya gagasan, pengertian. Kata kerja Yunani oida yang mengetahui, melihat dengan budi. Kata logi yang berasal dari bahasa Yunani logos yang artinya pengetahuan. Jadi ideologi mempunyai arti pengetahuan tentang gagasan-gagasan, pengetahuan tentang ide-ide, science of ideas atau ajaran tentang pengertian-pengertian dasar. Dalam pengertian sehari-hari menurut Kaelan idea disamakan artinya dengan cita-cita (Usman, 1993).

Secara umum dapat ditarik kesimpulan bahwa Ideologi adalah kumpulan gagasan-gagasan, ide-ide, keyakinan-keyakinan yang menyeluruh dan sistematis, yang menyangkut berbagai bidang kehidupan manusia. Notonegoro sebagaimana dikutip oleh Kaelan mengemukakan, bahwa Ideologi negara dalam arti cita-cita negara atau cita-cita yang menjadi dasar bagi suatu sistem kenegaraan untuk seluruh rakyat dan bangsa yang bersangkutan pada hakikatnya merupakan asas kerokhanian yang antara lain memiliki ciri:

a. Mempunyai derajat yang tertinggi sebagai nilai hidup kebangsaan dan kenegaraan;

b. Mewujudkan suatu asas kerokhanian, pandangan dunia, pedoman hidup, pegangan hidup yang dipelihara, dikembangkan,

dilestarikan kepada

diamalkan, berikutnya, diperjuangkan dan dipertahankan dengan kesediaan berkorban.

3. Nilai-nilai dalam pancasila

Sila Pertama Ketuhanan Yang Maha Esa (Nilai Ketuhanan), yaitu:

a. Percaya dan takwa kepada Tuhan YME sesuai dengan agama dan kepercayaan masing-masing.

b. Hormat menghormati dan bekerjasama antara pemeluk agama.

c. Saling menghormati dan kebebasan menjalankan ibadah sesuai dengan agama dan kepercayaan masingmasing.

d. Menghargai setiap bentuk ajaran agama dan kepercayaan orang lain.

e. Tidak memaksakan suatu agama dan kepercayaan kepada orang lain.

f. Berhenti saling menyakit, mulailah saling menghargai.

g. Berhenti saling merendahkan, mulailah menghormati perbedaan.

h. Berhenti takabur, mulailah bersyukur. Sila Kedua : Kemanusiaan Yang Adil dan Beradab (Nilai Kemanusiaan), yaitu:

a. Mengakui persamaan derajat, persamaan hak dan persamaan kewajiban antara sesama manusia.

b. Saling menyintai sesama manusia.

c. Mengembangkan sikap tenggang rasa.

d. Tidak semena-mena terhadap orang lain.

e. Menjunjung tinggi nilai kemanusiaan.

f. Gemar melakukan kegiatan kemanusiaan diartikan suka sekali melakukan kegiatan kemanusiaan sehingga setiap setiap manusia dapat hidup layak, bebas, dan aman.

g. Berani membela kebenaran dan keadilan. 
h. Bangsa indonesia merasa dirinya sebagai bagian dari seluruh umat manusia, karena itu dikembangkan sikap saling menghornati dengan bangsa lain.

i. Stop marah-marah, mulailah bersikap ramah.

j. Berhenti memaki, mulailah memakai hati.

k. Berhenti curiga, mulailah menyapa .

Sila Ketiga : Persatuan Indonesia, yaitu:

a. Menempatkan persatuan, kesatuan, kepentingan serta keselamatan bangsa dan negara diatas kepentingan pribadi atau golongan.

b. Rela berkorban untuk kepentingan bangsa dan negara.

c. Cinta tanah air dan bangsa.

d. Bangga sebagai bangsa Indonesia bertanah air Indonesia.

e. Memajukan pergaulan demi persatuan dan kesatuan bangsa yang berBhinneka Tunggal Ika.

f. Berhenti berseteru, mulailah bersatu.

g. Berhenti memaksakan, mulailah berkorban.

h. Berhenti mencari perbedaan, mulailah bergandeng tangan.

Sila Keempat: Kerakyatan yang Dipimpin oleh Hikmat Kebijaksanaan dalam Permusyawaratan/Perwakilan, yaitu:

a. Mengutamakan kepentingan negara dan masyarakat

b. Tidak memaksakan kehendak kepada orang lain

c. Mengutamakan musyawarah dalam mengambil keputusan untuk kepentingan bersama.

d. Dengan itikad baik dan rasa tanggung jawab menerima dan melaksanakan hasil keputusan musyawarah. e. Berhenti silang pendapat, mulailah mencari mufakat

f. Berhenti besar kepala, mulailah berlapang dada

g. Berhentilah bersilat lidah, mulailah bermusyarah

Sila Kelima : Keadilan Sosial Bagi

Seluruh Rakyat Indonesia, yaitu:

a. Menjaga keseimbangan antara hak dean kewajiban

b. Bersikap adil

c. Menghormati hak-hak orang lain

d. Tidak bersikap boros

e. Tidak bergaya hidup mewah

f. Tidak merugikan kepentingan umum

g. Suka berkerja keras

h. Bersama-sama berusaha mewujudkan kemajuan yang merata dan berkeadilan sosial

i. Berhenti malas, mulailah bekerja keras

j. Stop diskriminasi, mulailah toleransi

k. Berhenti menang sendiri, mulailah berbagi (Jakni, 2014)

Berdasarkan pemantauan dan pengamatan, selama berlangsungnya kegiatan, perhatian para peserta terhadap materi-materi yang disampaikan cukup tinggi. Hal ini dapat dilihat dari tingginya perhatian para peserta dan banyaknya para peserta yang mengajukan pertanyaan. Serta dapat dilihat pada diskusi tanya jawab antusias para siswa cukup tinggi dan ketika diajukan pertanyaan balik para siswa menjawab dengan baik dan penuh semangat. Serta dilihat dari hasil perbandingan Tes Awal (Pre Test) dan Tes Akhir (Post Test) yang diajukan peningkatan kemampuan siswa dalam menjawab soal meningkat dengan baik (Gambar 3 dan 4). 


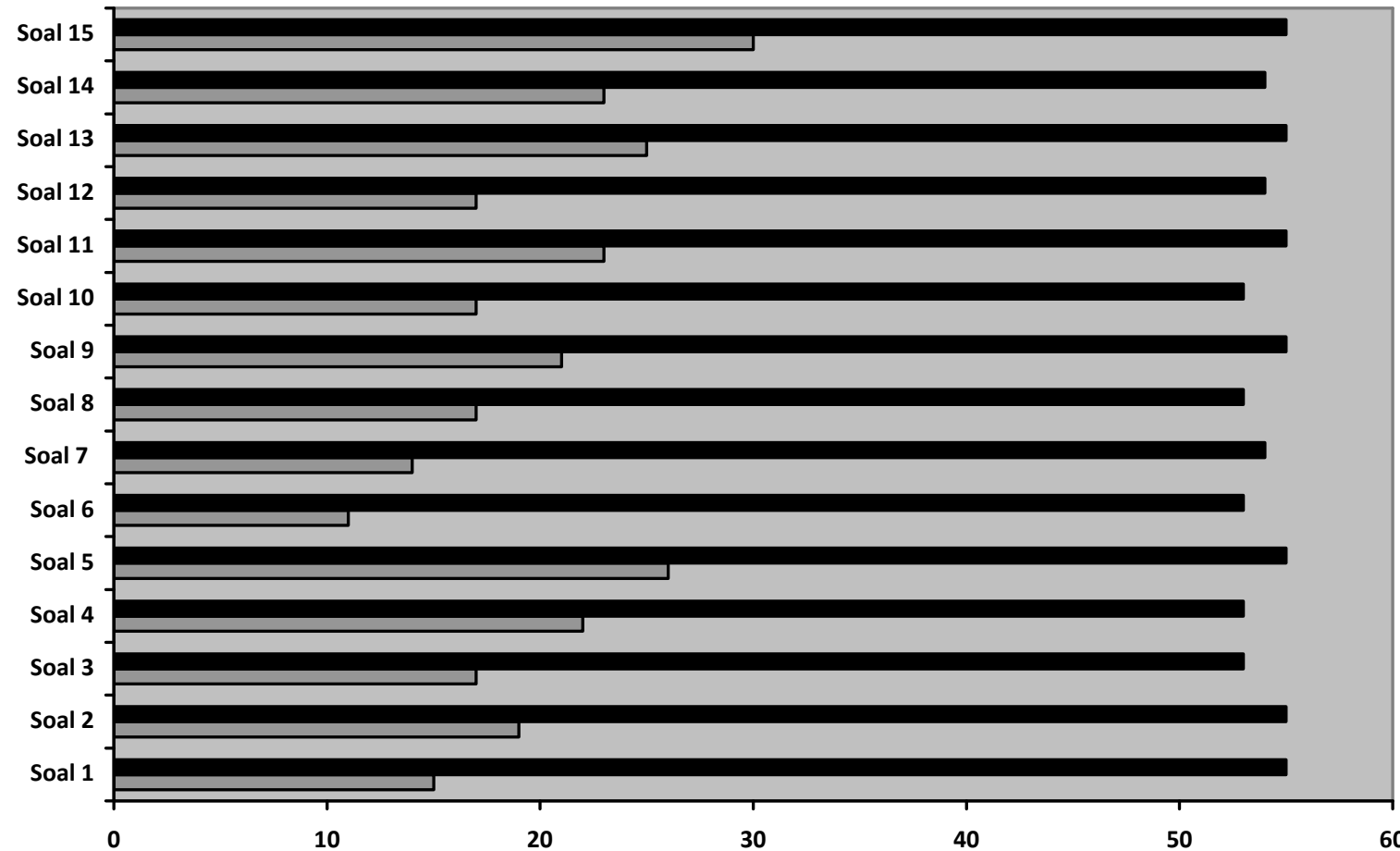

Gambar 3. Jumlah Peserta Menjawab Benar (Pretes dan Postes)

Keterangan :
Jumlah Soal
Jumlah Peserta
: 15 Soal
: 55 Orang
Grafik hitam : peserta menjawab benar (pretes)
Grafik abu-abu : Peserta menjawab benar (postes)

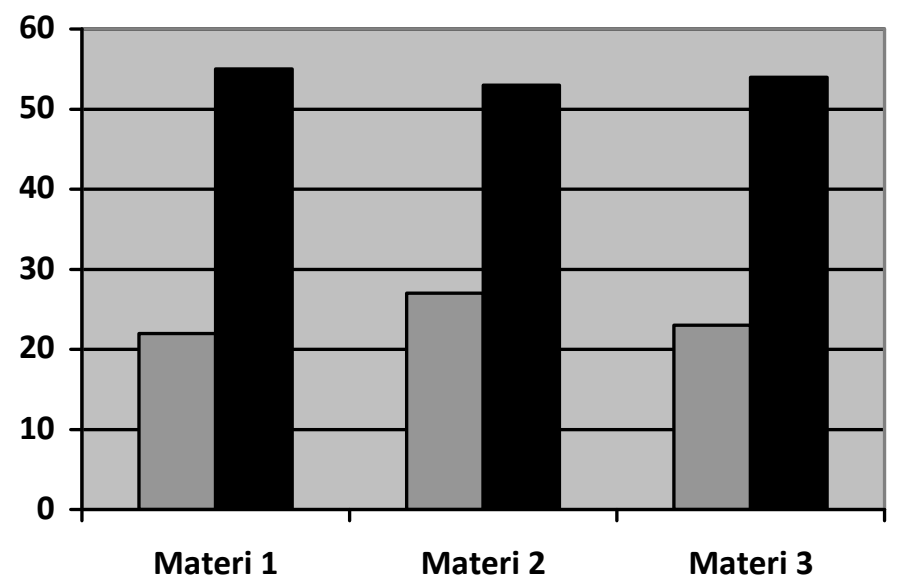

Keterangan :

Materi 1 : Pancasila sebagai Dasar Negara

Materi 2 : Pancasila sebagai Ideologi Negara

Materi 3 : Nilai-Nilai Pancasila

Peserta : 55 Orang

Grafik Hitam : Peserta Menjawab Benar (pretes)

Grafik abu-abu : Peserta Menjawab Benar (postes)

\begin{tabular}{|c|c|c|c|}
\hline & $\begin{array}{l}\text { mite } \\
\text { ii } 1\end{array}$ & $\begin{array}{l}\text { mate } \\
\text { ti2 }\end{array}$ & $\begin{array}{l}\text { mine } \\
\text { ri } 3\end{array}$ \\
\hline E Le's awal & 73 & 37 & 23 \\
\hline wes, nkhir & h. & 23 & 24 \\
\hline $\begin{array}{c}\text { nersentase } \\
\text { keriailkan }\end{array}$ & $55 \%$ & $47 \%$ & $56 \%$ \\
\hline
\end{tabular}

Gambar 4.Persentase Kenaikan Jumlah Peserta Menjawab Benar 


\section{J URNAL PENGABDIAN MASYARAKAT BORNEO (e-ISSN: 2579-9797) \\ Diterima: Maret 2017 \\ Disetujui: Juni 2017}

PENUTUP

Berdasarkan hasil yang dicapai, dapat disimpulkan bahwa dilihat dari evaluasi awal dan evaluasi akhir diperoleh hasil yang meningkat secara signifikan sehingga dapat dikatakan bahwa penyuluhan merupakan salah satu cara yang cukup efektif untuk memberikan pemahaman tentang nilai-nilai yang terdapat didalam Pancasila. Harapannya adalah dengan adanya kegiatan ini, maka materi yang didapatkan dari penyuluhan ini dapat diimplementasikan oleh OSIS dan Panitia Ekstrakulikuler lainnya dalam pola perilaku mereka dalam kehidupan berbangsa, bernegara dan bermasyarakat.

\section{UCAPAN TERIMAKASIH}

Pada kesempatan ini dengan segala kerendahan hati, kami ingin menyampaikan ucapan terima kasihsebesar-besarnya kepada:

1. Ibu Prof. Susi Endrini Ssi, MSc, PhD selaku Rektor Universitas YARSI;

2. Bapak dr. H. Sonny Pamudji Laksono, MKes, AIFM, selaku Wakil Rektor III ex officio Ketua Lembaga Pengabdian Masyarakat (LPM);

3. Ibu Dr. Ely Alawiyah Jufri, S.H.,M.H., selaku Dekan Fakultas Hukum Universitas YARSI;

4. Bapak Drs.Ansor,M.Pd, selaku Kepala Sekolah Menengah Kejuruan (SMK) Negeri 39

Jakarta;

5. Bapak Zulfikar,S.Pd,M.T, selaku Wakil Kepala Sekolah Sekolah Menengah Kejuruan (SMK) Negeri 39 Jakarta;

6. Abdul Salam dan Rizal Adi Santoso keduanya adalah mahasiswa Fakultas
Hukum Universitas YARSIyang telah membantu pelaksanaan kegiatan.

Semoga kegiatan ini bermanfaat bagi kita dalam rangka meningkatkan pengetahuan dan pemahaman tentang nilai-nilai Pancasila.

\section{DAFTAR PUSTAKA}

Baehaqi, D. A. (2014) Pendidikan Kewarganegaraan, Jakarta: Kaukaba.

Bakry, N. (2014). Pendidikan Pancasila, Jogjakarta: Pustaka Pelajar.

Jakni. (2014). Pendidikan Kewarganegaraan Perguruan Tinggi, Jakarta: Alfabeta.

Hariyanto. (2011). Ideologi Pancasila, Jakarta: Intrans

Hazairin. (2002). Demokrasi Pancasila, Jakarta: Rineke Cipta

Karim, M. A. (2004) Menggali Muatan Pancasila dalam Perspektif Islam, Jogjakarta: Sunan Kalijaga Press

Kartohadiprodjo, S. (2010) Pancasila sebagai Pandangan Hidup Bangsa Indonesia, Jakarta: Gatra Pustaka.

Latif, Y. (2015) Revolusi Pancasila, Jakarta: Mizan.

Maswardi. (2015). Moral Pancasila Jati Diri Bangsa: Aktualisasi Ucapan Dan Perilaku Bermoral Pancasila, Jakarta, Calpulis

Kaelan. (2002). Filsafat Pancasila, Yogyakarta: Paradigma. 
Kaelan. (2010). Pendidikan Pancasila, Yogyakara: Paradigma.

Pakan Lalangi, D. (2015). Kembali ke Jati Diri Bangsa, Jakarta: Kembali ke Jati Diri Bangsa: Menegakkan Sumpah Pemuda, Pancasila, Proklamasi, UUD 1945, Jakarta: Kompas.

Qomaruzzaman, B. (2011). Pendidikan Karakter Berbasis Pancasila, Jakarta: Perfect Binding.

Riyanto, A. (2015). Kearifan LokalPancasila. Butir-Butir Filsafat Keindonesiaan. Yogyakarta: Kanisius.

Said Ali, A. (2009). Negara Pancasila. Jakarta: LP3ES

Sutrisno, S. (2006). Filsafat dan Ideologi Pancasila. Yogyakarta: Andi Ofset.

Undang Undang Dasar 1945

Undang-Undang No. 20 Tahun 2003Tentang Pendidikan Nasional

Winarno. (2006). Pendidikan Kewarganegaraan Perguruan Tinggi, Jakarta: Bumi Aksara. 